\title{
BMJ Open Pleasure and practice: a qualitative study of the individual and social underpinnings of shisha use in cafes among youth in the UK
}

\author{
Ambrose Evarls K Mugyenyi, ${ }^{1}$ Jessica E Haberer, ${ }^{2}$ Ivy O'Neil ${ }^{3}$
}

To cite: Mugyenyi AEK, Haberer JE, O'Neil I. Pleasure and practice: a qualitative study of the individual and social underpinnings of shisha use in cafes among youth in the UK. BMJ Open 2018;8:e018989. doi:10.1136/ bmjopen-2017-018989

- Prepublication history for this paper is available online. To view these files, please visit the journal online (http://dx.doi. org/10.1136/bmjopen-2017018989).

A version of this paper was submitted in partial fulfilment for the requirement of MSc. Public Health, Health Promotion, Leeds Beckett University, UK September 2015.

Received 5 September 2017 Revised 16 February 2018 Accepted 19 February 2018

Check for updates

${ }^{1}$ Outreach department, Infectious Diseases Institute, Kampala, Uganda

${ }^{2}$ Department of Medicine, Havard Medical School,

Massachusetts General Hospital, Boston, Massachusetts, USA

${ }^{3}$ Health Promotion Department, Leeds Beckett University, Leeds, UK

Correspondence to Mr Ambrose Evarls K Mugyenyi; omugyenyia@yahoo.com

\section{ABSTRACT}

Objectives To explore (1) the social function of shisha cafes for young people living in the UK and (2) other alternative activities (existing or potential) that do not involve tobacco smoking.

Methods We conducted qualitative interviews with young adults (age 18-30) in Leeds, UK. Snowballing sampling was used in selecting the participants. Interviews were audio-recorded and explored the perspectives and experiences of young people in as well as potential alternative activities. Data were transcribed and analysed thematically.

Results Shisha use plays a central role in social interactions. Youth described using shisha because of emotional and sensory pleasure. Shisha use was implicitly endorsed by respected professionals, such as doctors and university lecturers, who were seen smoking it. Most, but not all, shisha smokers acknowledged that shisha use is harmful. Suggestions for reducing shisha use included use of non- tobacco alternatives, legislation to reduce access and alternative means for socialising, such as sports. Conclusion For young people in the UK, the known health dangers of shisha are outweighed by its social benefits and shisha is perceived as acceptable. Interventions to reverse the increase in shisha cafes should focus on both individual smoker as well as the community, without sacrificing the importance of social interactions.

\section{INTRODUCTION}

Shisha is a tobacco product that is smoked communally in a water pipe, narghile or hookah. Shisha smoking has origins in the Middle East, South East Asia and Northern Africa. ${ }^{1}$ It commonly takes place in a cafe setting/restaurant ${ }^{2}$ or other social gatherings over one or more hours. Like any tobacco smoking, shisha contains harmful materials such as carbon monoxide, nicotine and lead among others. ${ }^{3-5}$ According to the first international conference on water pipe tobacco research held in 2013, shisha smoking is a worldwide epidemic that needs urgent public health attention. ${ }^{6}$ Shisha smoking is a particularly widespread practice among young people. ${ }^{78}$ Studies from two universities in
Strengths and limitations of this study

- This study is one of the few studies done in the UK with an aim of exploring the use of niche tobacco, a case of young people's perception of shisha cafes.

- All the participants recruited were found to be students; results may not reflect the views of young people who were not in school.

- Majority of participants were South Asians; results may not necessarily represent the views of all young people in the UK.

America found that the prevalence of any lifetime hookah use was 25\%-28\% among university students, ${ }^{9}{ }^{10}$ while studies from the UK indicated that shisha smoking was between $11 \%$ and $18 \%$ among university students and $8 \%$ among secondary school students. ${ }^{1112}$ Other studies have shown that shisha smoking is more in the general population than in university students, ${ }^{1314}$ and shisha smoking starts at a mean age of 18.7 years, ${ }^{2}$ meaning that interventions to prevent the usage of shisha should start at an early age.

Research to date suggests that shisha use among young people is promoted primarily through peer influence, ${ }^{12} 1516$ as well as perceived benefits, such as reduced anxiety and entertainment. ${ }^{17-19}$ Many young people learn to smoke from friends, especially in high school or university. ${ }^{17}$ Youth are either taken to shisha cafes by their friends to smoke or they watch their friends smoke at their homes or at school. ${ }^{17}$ Shisha use is also promoted through flavoured tobacco products, ${ }^{57820}$ use of the internet ${ }^{921-24}$ and gaps in implementation of smoke-free policies. Cases of non-compliance with smoke-free legislation among the owners of shisha cafes have been reported..$^{22} 25$ Interventions targeting these reasons for shisha use have not been successful to date; additional approaches are needed. 
Shisha is well known to carry important meaning socially and among families, ${ }^{76-28}$ yet little research has explored how this meaning could inform shisha cessation interventions. Given the high prevalence of shisha use among youth, we conducted qualitative interviews of people aged 18-30 years in the UK to explore the social functions ascribed to shisha cafes with a goal of identifying areas of intervention.

\section{METHODS \\ Participants}

Inclusion criteria for this study were being 18-30years of age, speaking English, smoking shisha in a shisha cafe at least once a week in the last 1 month, having lived in Leeds, UK, for more than 1 year and being willing to provide signed informed consent. To recruit participants, one shisha smoker was initially identified from a shisha cafe in an inner city neighbourhood of Leeds who then identified friends for potential recruitment. These friends also identified their respective friends for potential recruitment (snowball sampling). Recruitment was performed with the help of community engagement officers at a local community centre.

\section{Data collection}

After obtaining informed consent, an interviewer trained in qualitative methodology collected sociodemographic information and conducted a single faceto-face semistructured interview with each participant that lasted 30-40 min. The interview consisted of openended questions aimed at exploring young people's perceptions of shisha cafes in Leeds, UK. The interview guide was piloted to help in testing the adequacy of the questions ${ }^{29}$ and modified accordingly. Data were collected at the office of the local community centre. Interviews were audio-recorded. The primary questions asked were: 'How do you feel when you visit this café?', 'What would you say has changed in your life when you started coming to this shisha café or any other?', 'What would you say is the significance that you attach to going to a shisha café?' and 'If there was to be an alternative to shisha, what would that be and why?' Additional questions were probes to further explore responses to the primary questions.

\section{Data analysis}

Recorded interviews were transcribed and the generated textual data were analysed using thematic approach. ${ }^{30} 31$ In brief, codes were initially identified from the first eight interviews. Following an iterative process with additional interviews, the codes were refined and formalised as a codebook. All interviews were then coded. Themes were generated and supported with illustrative quotations from the interviews. Participants were enrolled until thematic saturation was achieved.

\begin{tabular}{|c|c|}
\hline Characteristic & $\mathrm{N}(\%)$ or mean (SD) \\
\hline Age (years) & 24.8 \\
\hline \multicolumn{2}{|l|}{ Gender } \\
\hline Male & 21 \\
\hline Female & 10 \\
\hline \multicolumn{2}{|l|}{ Race/ethnicity } \\
\hline South Asian & 16 \\
\hline Whites & 8 \\
\hline Black & 7 \\
\hline \multicolumn{2}{|l|}{ Marriage status } \\
\hline Single & 26 \\
\hline Married & 5 \\
\hline \multicolumn{2}{|l|}{ Occupation } \\
\hline Student & 27 \\
\hline Working & 4 \\
\hline
\end{tabular}

\section{RESULTS}

\section{Participants}

A total of 48 participants were identified and screened. Of these, 31 enrolled in the study. Eight people declined due to lack of time for interviews, five did not give any reason and four people were not comfortable to be interviewed by a stranger. Participant sociodemographic characteristics are shown in table 1 . The majority were single, male students in their 20s. Approximately half were South Asian, with the remainder split between blacks and whites.

\section{Themes}

The following themes were identified: (1) shisha use plays a central role in social interactions, (2) shisha cafes are pleasurable, (3) shisha cafes are implicitly sanctioned when used by respected professionals, (4) most, but not all, acknowledge that shisha cafes are harmful and (5) shisha cafe use could be reduced through efforts aimed at the individual and the community.

Shisha use plays a central role in social and cultural interactions Most participants used shisha in cafes, which served as a place where young people could meet to socialise.

I like going to shisha cafés because I meet different people while I am there. We share different issues including school, friendship and even families-Male, 27 years old

Some female participants of South Asian origin highlighted that shisha cafes are the only places they can socialise with boys. One of the participants said:

My father does not allow boys to come to visit me. The only place I can meet the boys is a shisha café because my father allows me to go there. This makes me interact with the boys and even share contacts. If you do not interact with boys, where do you get a 
man to marry you in future? So, cafés do it well for me-Female, 20 years old

Many participants said that shisha cafes are relaxing settings where they can meet with friends and enjoy time together. They emphasised the ability to develop their social networks through patronage of different cafes. One participant said:

I sometimes travel a far distance from my home to meet up with my friends in different cafes. It's good to visit other shisha cafes that I am not used to as this increases on the network of friends which relaxes my mind-Male, 18 years old

This network of friends, however, can have negative influence as well. Other participants stated that they used shisha out of peer pressure, rather than a personal desire to use it. They go to shisha cafes to be with their friends and end up smoking while there.

I have friends who smoke shisha in shisha cafes and I go with them too. When I reach these cafes, I have to take shisha as well because all my friends are taking shisha—Female, 18 years old

Some participants used shisha outside of cafes. For instance, shisha may be served at important cultural functions like wedding functions or burial functions. It functions as a signal of welcoming, complementing other activities like watching TV or having a drink. In these settings, participants viewed shisha smoking as a show of respect. This was more common in South Asians compared with other cultures.

If my friends come to visit me, I have to prepare them shisha. When preparing food, I have to prepare shisha as well such that we as a family share with the visitors- Male, 20 years old

...... Sometimes just to change home environment, my dad takes us out to shisha cafés where we catch up with other friends and peers-Male, 24 years old

\section{Shisha cafes are pleasurable}

In addition to enabling social interaction, shisha cafes brought participants pleasure. Participants described the emotional benefits derived from the experience. One participant stated:

When I am stressed, I go to a shisha café. When I am there, I meet with my friends and I share with them my problems and I become psychologically fineFemale, 19 years old

Participants also found sensory pleasure through use of shisha. They stated that different flavours put in shisha and the soothing noise of bubbling water coming out of shisha apparatus enticed them to frequent shisha cafes.

I like different flavours in the shisha. I cannot even take a single day without going to a shisha café because of this flavour. Pineapple flavour is my favourite but there are different flavours-Male, 25 years old

You can imagine the kind of sound that come from bubbling water in the shisha machine, very relaxing, the sweet smell coming out while smoking. A very sweet smell indeed. I enjoy that all the time-Female, 18 years old

\section{Shisha cafes are implicitly sanctioned when used by respected} professionals

Some participants reported that professionals including doctors, public health officers and university lecturers smoke shisha. Participants expressed respect for these individuals and felt that shisha must be acceptable if they were using it. One participant said:

I have friends who are doctors and lecturers who smoke shisha with me. If a doctor can smoke shisha, who am I not to take shisha? These are respected people and we have to believe in what they do-Male, 25 years old

This implicit endorsement of shisha remained even when participants acknowledged the negative health effects of smoking shisha. The behaviour of these respected professionals was seen as an endorsement of safety and/or acceptability of many participants.

Doctors always tell us not to smoke but they smoke, they tell us not to take alcohol but they take it. Some of them even take shisha too. I know all these risks are there but I will keep taking my shisha as doctors and other professionals do-Male, 20 years old

Most, but not all, shisha smokers acknowledge that shisha cafes are harmful

Many participants clearly stated that shisha smoking has many negative consequences to their physical health. One participant said:

A few months ago, I started experiencing sleepless nights and increased heart rate when I am climbing a steep slope. This started months after start of shisha use-Male, 20 years old

Another participant said:

I used to be a footballer and before I began using shisha, I used to run without any problem but when I began using shisha, my ability to run began to decrease-Male, 21 years old

Many participants specifically felt that shisha puts them at risk of getting cancer, dental problems and cardiovascular diseases.

I have read from different sources that shisha smoking predisposes people who use it to different diseases including cancer of the lungs and cancer of the mouth-Male, 23 years old 
Shisha cafe use could be reduced through efforts aimed at the individual and the community

When asked about potential ways to reduce shisha use, participants felt that non-tobacco alternatives could be offered in shisha cafes that preserved the ritual of shisha smoking.

I would use any alternative without tobacco comfortably if the alternatives were served in shisha cafés, share it as we do with shisha but more safety measures should be put to avoid possible cross infections from one person to the other while sharing the mouthpiece-Male, 22years old

However, other participants believed that non-tobacco alternatives would not be helpful. Rather, cigarette cessation programmes should be adapted to help with quitting smoking of any kind.

I am a shisha smoker but I want to stop smoking completely. Alternatives should not be a priority to any person. I believe that smoking shisha is not good and to all people who smoke should be supported to stop smoking completely—Female, 19 years old

Some participants also advocated for laws to reduce shisha access.

I smoke because I have a right to do anything I want. I propose that excessive rights especially those that make people vulnerable should be reduced so as to have a healthy society. Otherwise, it becomes hard to convince people not to take shisha-Male, 24 years old

Regulations, however, would have to be specific to shisha, and some participants did not think general tobacco legislation applied.

In UK, there is a general regulation about tobacco use but i think specific regulations should be adopted so as to reduce shisha use in our communitiesFemale, 19 years old

Another participant believed that use of their peers to pass on information that would help peers to change their behaviour would be of help.

Use of people who previously used shisha in their life in giving information about the effects of shisha to fellow youth would be of help-Female, 21 years old

Finally, other participants suggested that alternative forms of socialising like sports and drama would help reduce shisha smoking.

Instead of going to shisha cafes as a socialising setting, we young people should get involved in sports like playing football, volleyball and netball or even get involved dance and drama aimed at educating other young people-Male, 21 years old

It's more healthy for us as young people to get involved in sports than smoking shisha-Female, 20 years old

\section{DISCUSSION}

This study found that shisha cafes provide a place for people to come together and find pleasure. Shisha use is voluntary, but also influenced by peers and other cultural expectations. Despite being pleasurable, many participants recognised the harm that can arise through shisha smoking and suggested various individual-level and community-level interventions to reduce it. Several promising interventions based on recommendations found on this study include peer-based interventions, alternative social events and informed legislation.

Peer-based interventions may be appealing as they have been shown to be acceptable, feasible and low cost in other settings, especially in comparison to more formal interventions that rely on professional healthcare providers. Peers share common characteristics, circumstances and experiences-all of which are thought to facilitate their acceptability to target populations and increase their influence and authenticity. ${ }^{32}$ Prior research has shown that people are more likely to hear and internalise messages, and thus to change their attitudes and behaviours, if they believe the messenger is similar to them and faces the same concerns and pressures that they face. ${ }^{33}{ }^{34}$ Importantly, peer-based interventions have been successful in projects aimed at reducing the incidence of cigarette smoking among young people. ${ }^{35} \mathrm{~A}$ study involving an informal, school-based, peer-led intervention for smoking prevention in adolescents showed a reduction of $22 \%$ in the odds of being a regular smoker compared with a control. ${ }^{36}$ These types of interventions could be readily adapted for use with shisha smoking.

Promotion of alternative social events is another promising intervention approach to reduce shisha smoking among young people. Examples include sports, music, dance and drama among others. The mechanism of effect may lie in the fact that social events enable people of compatible backgrounds to come together to achieve a common goal. ${ }^{37}$ For example, some studies on sports show that participants are linked by shared perspectives, language and activities, thus creating a shared network and bonds that go beyond a desire to compete. ${ }^{38}$ Other studies on sport participation also place emphasis on the value of shared experiences and linkages to others. ${ }^{39}$ Sports may also be used to pass on information in different areas. Educative sessions, for instance, may be provided during or after sport events. Coaches, teammates and other respected persons may serve as guest speakers to engage the audience. This approach was taken in India where sexual and reproductive health including HIV/ AIDS and life skills to empower youth has been integrated with sports. ${ }^{40}$ Drama has been widely employed in prevention of HIV/AIDS through community mobilisation and raising awareness in Uganda and South Africa. ${ }^{41}$ Also, in a study from India, use of information, education and communication activities in the form of drama and folk dances have shown success in increasing awareness about HIV/AIDS from $58 \%$ to $70 \%$ and in increasing knowledge 
regarding prevention of HIV by using condoms from $42 \%$ to $61 \%$. $^{42}$

Informed legislation specific to shisha maybe a third avenue for reducing use of shisha. Major breakthroughs regarding public health policies in tackling cigarette smoking have been seen in many countries of the world, including the UK. Some examples are smoking bans in public places, tax policies and limits on smoking advertisements. ${ }^{43}$ Several studies aimed at reducing tobacco use globally have shown that increasing taxes on tobacco products can be used as a tobacco control strategy as long as this strategy is well implemented. ${ }^{44}$ High prices can greatly reduce tobacco use. ${ }^{45}$ Studies from high-income countries find that an increase of $10 \%$ in price will reduce the overall use of tobacco by $4 \%$ on average ${ }^{45}$; results were even more pronounced in low/middle-income countries. However, most of the regulations and policies are focused on cigarettes rather than other types of tobacco products like shisha. ${ }^{76}$ In many countries including the UK, shisha is exempted from tobacco policies including reduced means of enforcing relevant policies to control tobacco. This situation has contributed to the explosion of shisha cafes and restaurants across the globe. ${ }^{746}$ Lessons learnt from anticigarette campaigns need to be applied to shisha smoking as well.

Two aspects of shisha warrant unique legislation. The first is related to packaging and associated warning labels. ${ }^{47}$ Globally, the packaging of cigarettes is nearly uniform with the same number of cigarettes in the similarly sized packs and cartons. In contrast, shisha is packaged in various amounts and in differently shaped containers. Moreover, shisha is often used communally and individuals may not see the packaging. Shisha users may therefore be unaware of the risks related to the tobacco, burning charcoal or even the infections that would spread through sharing of the waterpipe ${ }^{78}{ }^{49}$; non-removable labelling may be needed for the waterpipes specifically. Recently, some countries have started to implement policies for warning labels on shisha packaging. In Turkey, for instance, legislation dictates that these labels should be placed on all the shisha packaging, covering at least $65 \%$ of the package. ${ }^{50}$ Second, flavoured shisha has a small amount of tobacco relative to the profit margin ${ }^{25}$; policies aimed specifically at tobacco only may therefore be inadequate and specific legislation aimed at flavoured shisha may be needed to be effective.

\section{CONCLUSION}

Shisha use is rising and may pose significant health risks for those who smoke it and those who are exposed to it. This study provides informative perspectives on the role shisha plays in social interactions, factors influencing shisha use and potential means for reducing it. Future work should focus on intervention development to prevent the negative individual and public health consequences of shisha use without sacrificing the importance of social interactions.
Acknowledgements The authors would like to acknowledge a local community centre in the UK for the support while collecting data, Asiimwe Caroline for support and guidance while writing this report and, lastly, the Commonwealth commission for the scholarship that made this study a success.

Collaborators Ivy 0'Neil: Principal Lecturer (Retired), Leeds Beckett University, UK. Email: i.oneil@leedsbeckett.ac.uk

Contributors Being the first author, AEKM designed, collected, analysed and interpreted the data. AEKM also drafted the manuscript. JEH provided significant support for analysis and manuscript preparation. 10 supervised and guided the first author throughout the whole process of coming up with the paper.

Funding This study was funded by Commonwealth Scholarship.

Competing interests None declared.

Patient consent Obtained.

Ethics approval Research Ethics of the Academic Unit at Leeds Beckett University and the local community centre

Provenance and peer review Not commissioned; externally peer reviewed. Data sharing statement No additional data available.

Open Access This is an Open Access article distributed in accordance with the Creative Commons Attribution Non Commercial (CC BY-NC 4.0) license, which permits others to distribute, remix, adapt, build upon this work non-commercially, and license their derivative works on different terms, provided the original work is properly cited and the use is non-commercial. See: http://creativecommons.org/ licenses/by-nc/4.0/

(C) Article author(s) (or their employer(s) unless otherwise stated in the text of the article) 2018. All rights reserved. No commercial use is permitted unless otherwise expressly granted.

\section{REFERENCES}

1. Akl EA, Ward KD, Bteddini D, et al. The allure of the waterpipe: a narrative review of factors affecting the epidemic rise in waterpipe smoking among young persons globally. Tob Control 2015;24(Suppl 1):i13-21.

2. Al-Naggar RA, Bobryshev YV, Anil S. Pattern of shisha and cigarette smoking in the general population in Malaysia. Asian Pac J Cancer Prev 2014;15:10841-6.

3. Al Rashidi M, Shihadeh A, Saliba NA. Volatile aldehydes in the mainstream smoke of the narghile waterpipe. Food Chem Toxicol 2008;46:3546-9.

4. Shihadeh A, Saleh R. Polycyclic aromatic hydrocarbons, carbon monoxide, "tar", and nicotine in the mainstream smoke aerosol of the narghile water pipe. Food Chem Toxicol 2005;43:655-61.

5. Rastam S, Ward KD, Eissenberg T, et al. Estimating the beginning of the waterpipe epidemic in Syria. BMC Public Health 2004;4:32.

6. World Health Organisation. WHO global report on mortality attributable to tobacco. Geneva: World Health Organisation, 2012.

7. Maziak W, Taleb ZB, Bahelah R, et al. The global epidemiology of waterpipe smoking. Tobacco control 2014.

8. Martinasek MP, McDermott RJ, Martini L. Waterpipe (hookah) tobacco smoking among youth. Curr Probl Pediatr Adolesc Health Care 2011;41:34-57.

9. Brockman LN, Pumper MA, Christakis DA, et al. Hookah's new popularity among US college students: a pilot study of the characteristics of hookah smokers and their Facebook displays. BMJ Open 2012;2:e001709.

10. Smith JR, Edland SD, Novotny TE, et al. Increasing hookah use in California. Am J Public Health 2011;101:1876-9.

11. Jackson D, Aveyard P. Waterpipe smoking in students: prevalence, risk factors, symptoms of addiction, and smoke intake. Evidence from one British university. BMC Public Health 2008;8:174.

12. Jawad M, Wilson A, Lee JT, et al. Prevalence and predictors of water pipe and cigarette smoking among secondary school students in London. Nicotine Tob Res 2013;15:2069-75.

13. Al-Naggar RA, Saghir FS. Water pipe (shisha) smoking and associated factors among Malaysian university students. Asian Pac J Cancer Prev 2011;12:3041-7.

14. Al-Naggar RA, Bobryshev YV. Shisha smoking and associated factors among medical students in Malaysia. Asian Pac J Cancer Prev 2012;13:5627-32.

15. Habibullah S, Ashraf J, Javed R, et al. Prevalence of Shisha smoking in college, university and Madarsa Students aged 20-25 years in Pakistan. Pak J Med Res 2013;52:3. 
16. Al-Turki YA. Smoking habits among medical students in Central Saudi Arabia. Saudi Med J 2006;27:700-3.

17. Sharma E, Clark PI, Sharp KE. Understanding psychosocial aspects of waterpipe smoking among college students. Am J Health Behav 2014;38:440-7.

18. Hammal F, Mock J, Ward KD, et al. A pleasure among friends: how narghile (waterpipe) smoking differs from cigarette smoking in Syria. Tob Control 2008; 17:e3.

19. Anjum Q, Ahmed F, Ashfaq T. Knowledge, attitude and perception of water pipe smoking (Shisha) among adolescents aged 14-19 years. $J$ Pak Med Assoc 2008;58:312.

20. Sutfin EL, Song EY, Reboussin BA, et al. What are young adults smoking in their hookahs? A latent class analysis of substances smoked. Addict Behav 2014;39:1191-6.

21. Nakkash RT, Khalil J, Afifi RA. The rise in narghile (shisha, hookah) waterpipe tobacco smoking: a qualitative study of perceptions of smokers and non smokers. BMC Public Health 2011;11:315.

22. Salloum RG, Osman A, Maziak W, et al. How popular is waterpipe tobacco smoking? Findings from internet search queries. Tob Control 2015;24:509-13.

23. Carroll MV, Shensa A, Primack BA. A comparison of cigarette- and hookah-related videos on YouTube. Tob Control 2013;22.

24. Saitta D, Ferro GA, Polosa R. Achieving appropriate regulations for electronic cigarettes. Ther Adv Chronic Dis 2014;5:50-61.

25. Maziak W, Nakkash R, Bahelah R, et al. Tobacco in the Arab world: old and new epidemics amidst policy paralysis. Health Policy Plan 2014;29:784-94

26. Maziak W, Ward KD, Eissenberg T. Interventions for waterpipe smoking cessation. Cochrane Database Syst Rev 2007:CD005549.

27. Carroll MV, Chang J, Sidani JE, et al. Reigniting tobacco ritual: waterpipe tobacco smoking establishment culture in the United States. Nicotine Tob Res 2014;16:1549-58.

28. Afifi R, Khalil J, Fouad F, et al. Social norms and attitudes linked to waterpipe use in the Eastern Mediterranean Region. Soc Sci Med 2013;98:125-34.

29. De Vaus D. Surveys in social research. UK: Routledge, 2013.

30. Attride-Stirling J. Thematic networks: an analytic tool for qualitative research. Qualitative Research 2001;1:385-405.

31. Ryan GW, Bernard HR. Techniques to identify themes. Field methods 2003;15:85-109.

32. Kerrigan DJ. Peer education and HIVIAIDS: Concepts, users and challenges: UNAIDS, 1999.

33. Sloane BC, Zimmer CG. The power of peer health education. J Am Coll Health 1993;41:241-5.

34. Milburn K. A critical review of peer education with young people with special reference to sexual health. Health Educ Res 1995;10:407-20.
35. Abernathy TJ, Bertrand DB. Preventing cigarette smoking among children: Results of the 4 year evaluation of the PAL program. Canadian J PH 1992;83:226-9.

36. Campbell R, Starkey F, Holliday J, et al. An informal school-based peer-led intervention for smoking prevention in adolescence (ASSIST): a cluster randomised trial. The Lancet 2008;371:1595-602.

37. Recours RA, Souville M, Griffet J. Expressed motives for informal and club/association-based sports participation. $J$ Leis Res 2004;36-1-22.

38. Maffesoli M. The time of the tribes: the decline of individuals in mass society: Sage, 1995.

39. Andrews DL, Loy JW. British cultural studies and sport: past encounters and future possibilities. Quest 1993;45:255-76.

40. Dudfield O. Strengthening sport for development and peace: national policies and strategies: Commonwealth Secretariat, 2014.

41. Mwansa D, Bergman P. Drama in HIV/AIDS prevention: some strength and weaknesses: a study in Botswana, Tanzania, South Africa, Kenya, Ethiopia and Uganda. Swedish Int Develop Coorper Agency 2011;2003:10.

42. Bhatia V, Swami HM, Kaur AP. An intervention study to enhance AIDS awareness among underprivileged population in Chandigarh. Indian $\mathrm{J}$ Dermatol Venereol Leprol 2004;70:87.

43. Note WT. Waterpipe tobacco smoking: health effects, research needs and recommended actions by regulators. Geneva: World Health Organization, 2005.

44. Ross HZ, Sharriff S, Gilmore A. Economics of tobacco taxation in Russia. Paris: International Union Against Tuberculosis and Lung Disease, 2008:4-5.

45. Smith K, Gilmore A, Chaloupka F, et al. IARC handbooks of cancer prevention: Tobacco control volume14: effectiveness of tax and price policies for control of tobacco. Lyon, France: International Agency for Research on Cancer, 2011.

46. Salloum RG, Nakkash RT, Myers AE, et al. Point-of-sale tobacco advertising in Beirut, Lebanon following a national advertising ban BMC Public Health 2013;13:534.

47. Bahelah R. Waterpipe tobacco labeling and packaging and World Health Organization Framework Convention on Tobacco Control (WHO FCTC): a call for action. Addiction 2014;109:333.

48. Sepetdjian E, Shihadeh A, Saliba NA. Measurement of 16 polycyclic aromatic hydrocarbons in narghile waterpipe tobacco smoke. Food Chem Toxicol 2008;46:1582-90

49. Knishkowy B, Amitai Y. Water-pipe (narghile) smoking: an emerging health risk behavior. Pediatrics 2005;116:e113-9.

50. Barnoya J, Navas-Acien A. Protecting the world from secondhand tobacco smoke exposure: where do we stand and where do we go from here? Nicotine Tob Res 2013;15:789-804. 